Article

\title{
Sorption Isotherm of Southern Yellow Pine-High Density Polyethylene Composites
}

\section{Feihong Liu ${ }^{1}$, Guangping Han ${ }^{1}$, , Wanli Cheng ${ }^{1}$ and Qinglin $\mathrm{Wu}^{2}$}

1 Key Laboratory of Bio-based Material Science and Technology (Ministry of Education), Northeast Forestry University, Harbin 150040, China; E-Mails: feihongliu8@ gmail.com (F.L.); nefucwl@nefu.edu.cn (W.C.)

2 School of Renewable Natural Resources, Louisiana State University Agricultural Center, Baton Rouge, LA 70803, USA; E-Mail: wuqing@1su.edu

* Author to whom correspondence should be addressed; E-Mail: guangping.han @ nefu.edu.cn; Tel.: +86-451-8219-1871; Fax: +86-451-8219-1938.

Academic Editor: Jérôme Chevalier

Received: 13 October 2014 / Accepted: 9 January 2015 / Published: 20 January 2015

\begin{abstract}
Temperature and relative humidity (RH) are two major external factors, which affect equilibrium moisture content (EMC) of wood-plastic composites (WPCs). In this study, the effect of different durability treatments on sorption and desorption isotherms of southern yellow pine (SYP)-high density polyethylene (HDPE) composites was investigated. All samples were equilibriumed at $20{ }^{\circ} \mathrm{C}$ and various RHs including $16 \%$, $33 \%, 45 \%, 66 \%, 75 \%, 85 \%, 93 \%$, and $100 \%$. EMCs obtained from desorption and absorption for different WPC samples were compared with Nelson's sorption isotherm model predictions using the same temperature and humidity conditions. The results indicated that the amount of moisture absorbed increased with the increases in $\mathrm{RH}$ at $20{ }^{\circ} \mathrm{C}$. All samples showed sorption hysteresis at a fixed RH. Small difference between EMC data of WPC samples containing different amount of ultraviolet (UV) stabilizers were observed. Similar results were observed among the samples containing different amount of zinc borate (ZB). The experimental data of EMCs at various RHs fit to the Nelson's sorption isotherm model well. The Nelson's model can be used to predicate EMCs of WPCs under different RH environmental conditions.
\end{abstract}

Keywords: wood-plastic composites; sorption isotherm; durability treatments; nelson's model 


\section{Introduction}

Wood-plastic composites (WPCs) are extensively used for decking, railing, and fencing [1]. When WPCs are used outdoors, they are subjected to a climate with moisture and temperature-fluctuations, ultraviolet (UV) radiation, and decay fungi. After exposure of WPCs to varying environmental conditions, especially UV radiation from sunlight, the composites will undergo photo-degradation leading to undesirable effects, including a loss in mechanical properties and surface quality, i.e., surface micro-cracking and color change [2-4]. The presence of moisture absorbed also aggravates this problem when WPCs are used for outdoor applications [5-7]. The existence of moisture in wood accelerates oxidation reaction, which is a direct consequence of photo-degradation [6]. The adverse effects of UV radiation on WPCs can be delayed or minimized with the use of UV stabilizers such as UV absorbers (UVA) and hindered amine light stabilizers (HALS) (free-radical scavengers). It was reported that the materials with UV stabilizers lightened less and showed less loss in mechanical properties compared with the materials without UV stabilizers [2]. Other studies showed that addition of HALS or UVA or both photo-stabilizers delayed and minimized the impacts of natural weathering on HDPE-wood fiber (WF) composites [8]. The stabilized HDPE-WF composite with UVA showed the best protection in the loss of flexural modulus among the test samples [8].

Another concern about the use of WPCs for outdoor applications is their fungal resistance. When the first generation of WPCs was applied into the market, it was considered to be immune to biological attack, because the fiber were encapsulated by plastic totally, and WPCs were water resistance. Actually, when WPCs are exposed in a humid atmosphere, its plastic-rich surface phase will delay the rate of moisture absorption; therefore the WPCs seem to be moisture resistance. However, it was reported that after a long-term exposure to high relative humidity $(\mathrm{RH})$ surrounding, the surface layer of WPCs showed higher moisture content and the moisture distributed uniformly through the cross section of WPCs [9]. The high moisture content will provide an indispensable element for the growth of fungi and other microorganisms. Craig M. Clemons have studied the effects of processing method and moisture history on laboratory fungal resistance of wood-HDPE composites [10]. The results showed that significant weight losses were found once the composite moisture content reached roughly $12 \%$ to $15 \%$, indicating severe decay [10]. Fungal degradation not only affected the aesthetic appearance of WPCs, but also decreased the mechanical properties and further affected the long-term performances of WPCs. Literatures showed that the inclusion of Zinc borate (ZB) can effectively prevent fungal decay and $\mathrm{ZB}$ will take at least 20 years to completely dissolve and leach from the material [11].

To date, many researches about the influence of adding ZB or UVA or HALS on the mechanical and weathering properties have been reported. However, the effects of adding ZB or UVA or HALS on the equilibrium moisture content (EMC) of WPCs under different RHs at a given temperature have not been reported yet.

Similar to solid wood, the wood component in WPCs absorbs and desorbs water molecules to be in equilibrium with the surrounding atmosphere, thus the EMC of WPCs varies with the change of the atmosphere. Mainly, the RH and temperature of the environment can affect EMC. The relationships between EMC and RH at given temperatures, i.e., sorption isotherms, greatly affect the performances of wood-based materials including strength and dimensional stability in their applications. Many studies have been done with the moisture sorption isotherm and the models to evaluate the EMC of 
solid wood [12-16]. However, reports on EMC of WPCs under different environments are limited, especially the isotherm models of EMC as a function of temperature and RH. Only Adebola studied the absorption and desorption performances of two commercial WPCs [17]. In his study, the experimental EMC data were compared with Hailwood-Horrobin $(\mathrm{H}-\mathrm{H})$ sorption model predictions using the same temperature and $\mathrm{RH}$. The results showed that the amount of moisture absorbed increased with the increase of $\mathrm{RH}$ at an average temperature of $23{ }^{\circ} \mathrm{C}$, and the predicted EMC values of WPCs deviated from the H-H model. The H-H model was shown to be ineffective in predicting the EMC of WPCs [17].

One of the most common used models to describe sorption isotherms is Nelson's model based on Gibbs free energy [18]. Wu applied this model to medium density fiberboards and oriented strand boards, and the results showed that it could be used to describe the sorption property of wood-based boards [19]. The similar results indicated that it also could be applied to straw particleboards [20]. Han et al. [21] compared the sorption property of sugarcane rind with that of wood strand for structural use. It demonstrated that the model could be used as a tool for predicting moisture change in wood-based products under varying environmental conditions. However, the applicability of Nelson's model to predict the sorption isotherm of WPCs is not clear yet.

Accordingly, the primary objectives of this study were to investigate: (a) the sorption and desorption properties of WPCs; (b) the effects of different durability treatments, i.e., the addition of ZB and UV stabilizers, on the EMC of WPCs under various RHs; and (c) the effectiveness of Nelson's model in predicting EMC of WPCs. In addition, sorption isotherms reproduced by Nelson's model of WPCs were compared with other composite materials and solid wood.

\section{Experimental}

\subsection{Raw Materials and Preparation}

High-density polyethylene (HDPE) (HD0760, density $=960 \mathrm{~kg} / \mathrm{m}^{3}$, melt flow index $(\mathrm{MFI})=$ $0.7 \mathrm{~g} / 10 \mathrm{~min}$ at $190{ }^{\circ} \mathrm{C} / 2.16 \mathrm{~kg}$ ) from ExxonMobile Chemical Co. (Houston, TX, USA) was used as a matrix. Southern yellow pine (SYP) wood flour with a particle size of 20 mesh was provided by American Wood Fiber Inc. (Schofield, WI, USA). Maleated polyethylene (MAPE) (EpoleneTM G2608 with molecular weight $=65,000 \mathrm{~g} / \mathrm{mol}, \mathrm{MFI}=6$ to $10 \mathrm{~g} / 10 \mathrm{~min}$ at $190{ }^{\circ} \mathrm{C} / 2.16 \mathrm{~kg}$ ) was applied to increase the compatibility between wood fibers and the plastic matrix. Zinc borate (ZB) as a preservative was purchased from the US Borax Co. (Greenwood Village, CO, USA). Lubricant (TPW 306) from Struktol Co. (Stow, OH, USA) was used for easy processing of the WPC profile. UVA (Tinuvin 326) and HALS (Tinuvin 783 and Chimassorb 944), supplied by Ciba Specialty Chemicals Inc. (Mississauga, ON, Canada), were chosen for this study. The UV absorber (Tinuvin 326) acts by absorbing UV radiation preferentially to polymers; and the two HALS classes (Tinuvin 783 and Chimassorb 944) are based on antioxidants. Colorant was also added to provide the composites with a wood-like appearance. All the chemical additives were used as received.

\subsection{Blend Design and Sample Fabrication}

The composite blends were prepared using a Leistritz Micro-27 co-rotating parallel twin-screw extruder (Leistritz Corporation, Allendale, NJ, USA). The extrusion temperatures were controlled at 
$155,160,165,170,170,170,160,150,150,150$, and $155^{\circ} \mathrm{C}$ from the feeing zone to die. The extruder rotation speed was set at $60 \mathrm{rpm}$. HDPE, wood flour, UV stabilizers, ZB, and other processing aids (MAPE 2\%, Talc 5\%, Lubricant 5\%, Colorant 2\%) were added to the extruder and thoroughly mixed. Profile extrusion was conducted using an Intelli-Torque Twin-Screw Extruder (CW Brabender Instruments; South Hanckensack, NJ, USA) and a die $(5 \mathrm{~mm} \times 50 \mathrm{~mm})$. The temperatures for the profile extrusion was from 150 (feeder), 165,160 , and $155^{\circ} \mathrm{C}$ (die). The profile was cut into various lengths for further testing after air cooling. Table 1 shows the design for various blends.

Table 1. Wood flour and high density polyethylene (HDPE) blend design for the wood-plastic composite (WPC) samples.

\begin{tabular}{cccccccc}
\hline $\begin{array}{c}\text { Material } \\
\text { type }\end{array}$ & \multicolumn{2}{c}{ UV stabilizer $(\mathbf{w t} \%)$} & $\begin{array}{c}\text { ZB } \\
\text { (wt\%) }\end{array}$ & $\begin{array}{c}\text { Wood flour } \\
(\mathbf{w t} \%)\end{array}$ & $\begin{array}{c}\text { HDPE } \\
(\mathbf{w t} \%)\end{array}$ & $\begin{array}{c}\text { Other processing aids } \\
\text { (wt\%) }\end{array}$ \\
\hline 1 & - & - & - & - & 55 & 31 & 14 \\
2 & 1 & - & - & - & 55 & 30 & 14 \\
3 & 2 & - & - & - & 55 & 29 & 14 \\
4 & - & 1 & - & - & 55 & 30 & 14 \\
5 & - & 2 & - & - & 55 & 29 & 14 \\
6 & - & - & 1 & - & 55 & 30 & 14 \\
7 & - & - & 2 & - & 55 & 29 & 14 \\
8 & 1 & - & - & 1 & 55 & 29 & 14 \\
9 & 2 & - & - & 2 & 55 & 27 & 14 \\
10 & - & 1 & - & 1 & 55 & 29 & 14 \\
11 & - & 2 & - & 2 & 55 & 27 & 14 \\
12 & - & - & 1 & 1 & 55 & 29 & 14 \\
13 & - & - & 2 & 2 & 55 & 27 & 14 \\
14 & - & - & & 1 & 55 & 30 & 14 \\
15 & - & - & & 2 & 55 & 29 & 14 \\
\hline
\end{tabular}

\subsection{EMC Measurements}

Four specimens from each of the material types were randomly selected and numbered and then combined to form one group. The size of all samples is $10 \mathrm{~mm} \times 10 \mathrm{~mm} \times 4 \mathrm{~mm}$. For absorption, eight groups of samples were randomly selected and oven dried at $70{ }^{\circ} \mathrm{C}$ for two days to reach the dry state. The remaining eight groups were conditioned over distilled water to reach the fiber saturation state for the desorption experiment. All groups of samples were conditioned at a relative humidity of $16 \%, 33 \%, 45 \%, 66 \%, 75 \%, 85 \%, 93 \%$, and $100 \%$ respectively. The RHs of $16 \%$ and $45 \%$ were achieved over sulfuric acid solutions with concentrations of $60 \%$ and $45 \%$, respectively. While the RH of $100 \%$ was generated through distilled water placed in desiccators when it reached the equilibrium state. Five desiccators charged with saturated salt solutions were used to obtain other five specified conditions. The weights of all specimens were measured after 4 months when the specimen reached equilibrium. After conditioning, the specimens were oven dried at $103{ }^{\circ} \mathrm{C}$ for $24 \mathrm{~h}$. The EMC of each specimen was calculated based on the oven dry weight using Equation (1). 


$$
E M C=\left(\frac{w_{t}}{w_{o}}-1\right) \times 100 \%
$$

where $w_{t}$ is the equilibrium weight of sample $(\mathrm{g})$ and $w_{o}$ is the oven dry weight of sample $(\mathrm{g})$.

\subsection{Nelson's Model}

Experimental data of EMC at various RHs were fit to the sorption isotherm model proposed by Nelson (1983). The model is of the form:

$$
\frac{R H}{100}=\exp \left\{\left(-\frac{W_{w}}{R T}\right) \exp \left[A\left(1.0-\frac{E M C}{M_{v}}\right)\right]\right\}
$$

where: $R H=$ Relative humidity in percent; $\exp =$ Exponential function; $M_{v}=$ Material constant which approximates the fiber saturation point for desorption (\%); $A=$ Natural logarithm of the Gibbs free energy per gram of sorbed water as RH approacheszero $\left(\Delta \mathrm{G}_{\mathrm{o}}\right.$, cal/g), i.e., $\mathrm{A}=\ln \left(\Delta \mathrm{G}_{\mathrm{o}}\right) ; R=$ Universal gas constant $\left(1.9858 \mathrm{cal} / \mathrm{mole} /{ }^{\circ} \mathrm{K}\right) ; T=$ Absolute temperature $\left({ }^{\circ} \mathrm{K}\right) ; W_{w}=$ Molecular weight of water $(18.1 \mathrm{~g} / \mathrm{mol})$. At a given temperature, the term $\left(-R T / W_{w}\right)$ becomes a constant, and then parameters $A$ and $M_{v}$ define the sorption isotherm. To determine the values of $A$ and $M_{v}$, a linear regression analysis was performed using Equation (3) with the measured EMC as the dependent variable and transformed RH, i.e., $\operatorname{Ln}\left[\left(-R T / W_{w}\right) \operatorname{Ln}(R H)\right]$ as the independent variable:

$$
E M C=M_{v}\left\{1.0-\frac{1}{A} \operatorname{Ln}\left[\left(-\frac{R T}{W_{W}}\right) \operatorname{LnRH}\right]\right\}
$$

\section{Results and Discussion}

\subsection{Sorption Isotherm of WPCs}

Figure 1, based on the EMC data both from absorption and desorption, shows that EMC values increased with increasing $\mathrm{RH}$ for all samples both from absorption and desorption. Notably, the EMC data achieved through the absorption process were lower than those obtained from desorption at the same RH, indicating sorption hysteresis. This result was similar to the previous studies on wood-based materials including oriented straw board (OSB), middle density fiberboard (MDF), and solid wood [18]. Compared to solid wood, WPCs are kind of more complex composites with a combination of wood fibers and thermoplastic polymers. For WPCs, wood fibers are partly encased by the plastic, so the pathway, which water molecules come through, is changed accordingly. For solid wood, water molecules diffuse through wood cell wall, capillary tubes, and micro-capillary tubes [1,2]. The routes of water molecules diffusion into WPCs are the gaps and the interfaces between wood fibers and plastic matrix resulted from poor interface compatibility and the micro-cracks formed in the process of compounding first. And then water molecules transmission was similar to solid wood when the moisture was captured by the wood fibers in the WPCs. Although the channels of moisture molecules coming into the WPCs and solid wood are different, water molecules are absorbed by the wood fibers finally. Therefore, the WPCs samples showed similar hysteresis phenomenon with solid wood resulting from the wood fibers in WPCs. 


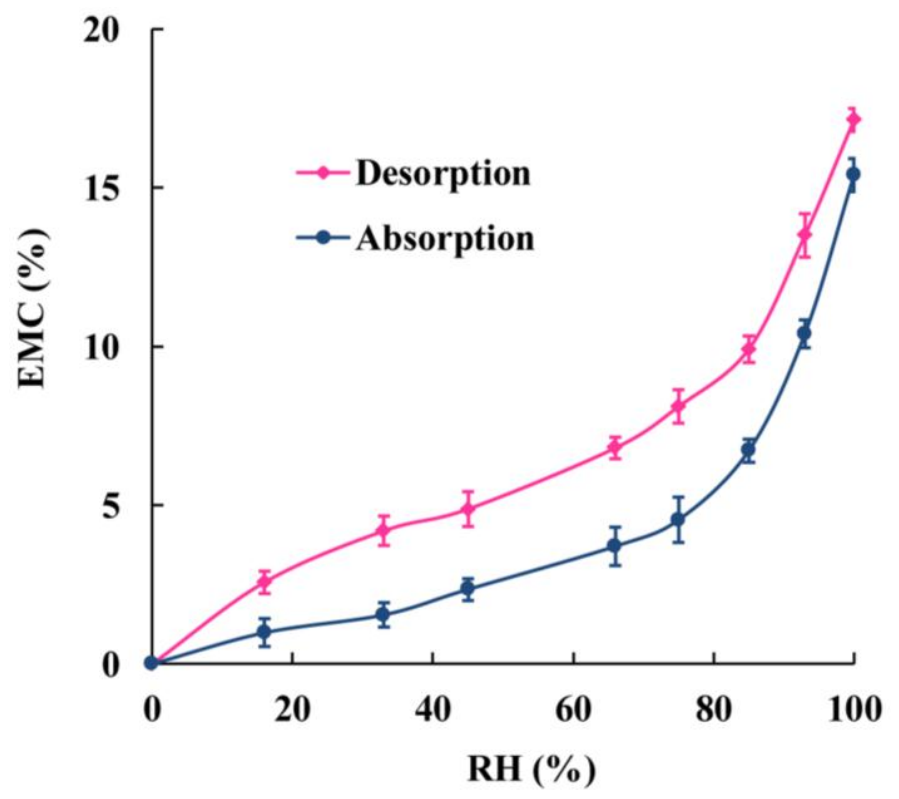

Figure 1. Typical sorption and desorption isotherms for type 1 WPC samples at $20{ }^{\circ} \mathrm{C}$. Material types refer to Table 1.

\subsection{Effects of Durability Treatment on the EMC of WPCs}

Figure 2 shows the EMC values achieved from absorption and desorption of WPC samples that contain Chi944 (HALS) UV-stabilizers. EMC values of WPCs were increased with the increase of RH for all samples both from desorption and absorption. For desorption, regardless of the amount of UV-stabilizers added, WPCs samples treated by Chi944 had approximately the same EMC data as the control samples (samples without any durability treatments) at a given RH. Similar case was observed for absorption. The effects of UV stabilizers Tin738 (UVA) on the EMC values of WPCs samples (Figure 3) were similar to that of Chi944. These two Figures suggest that effects of UV-stabilizers on the EMC values of WPCs were slight. Figure 4 shows that the EMC values of WPCs were not affected by the addition of $\mathrm{ZB}$ for both absorption and desorption.
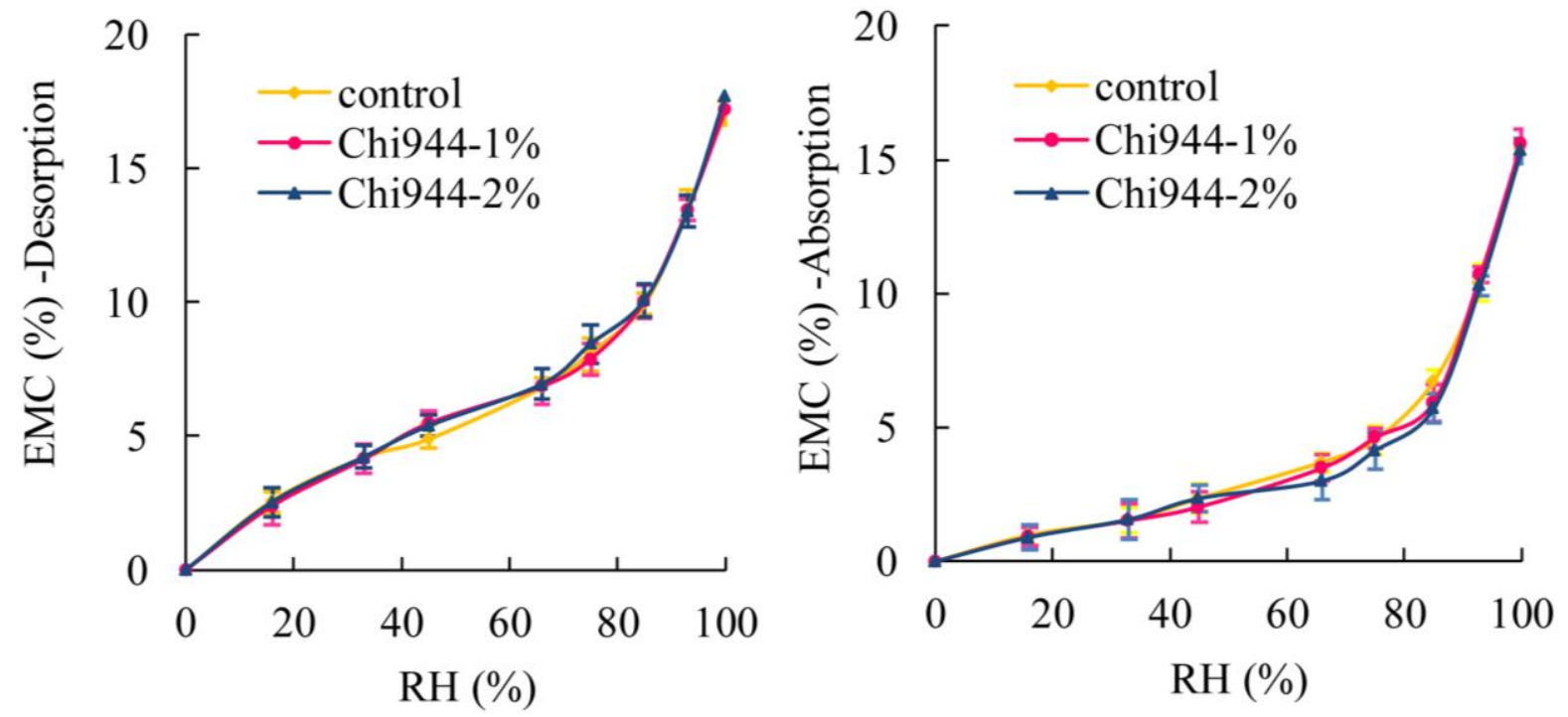

Figure 2. Effects of UV stabilizers Chi944 on equilibrium moisture content (EMC) of WPCs. 
Different durability treatments had only slight effects on the EMC of the composites. The moisture uptake is almost a constant when the amount of wood fibers in WPCs is fixed. In this study, the wood content was $55 \%$ by weight for all material types while the maximum content of ZB or UV stabilizers was only $2 \%$, which is so small that the effects of them on the moisture sorption property of WPCs could be ignored. In other words, the sorption isotherm of WPCs in the study was dominated by wood fibers.
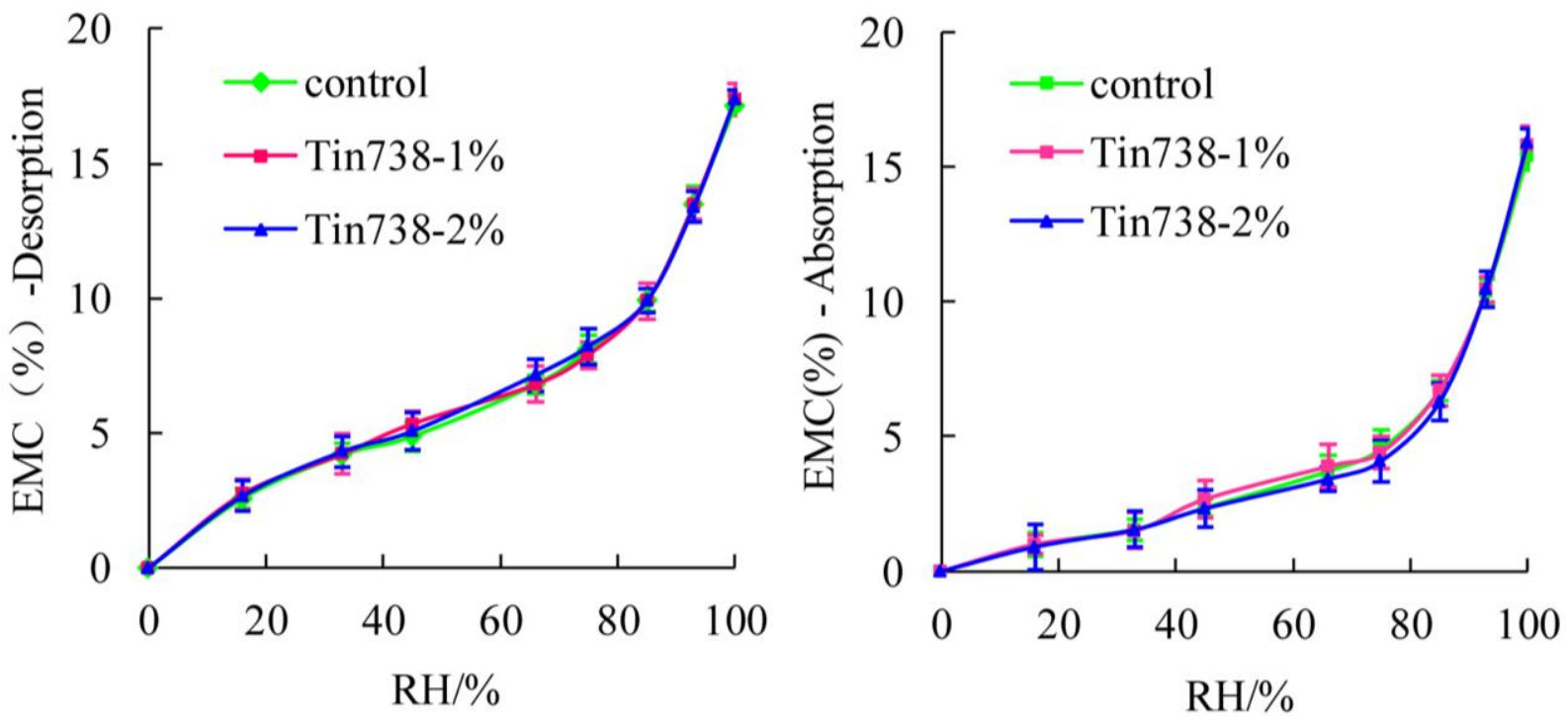

Figure 3. Effects of UV stabilizers Tin738 on EMC of WPCs.
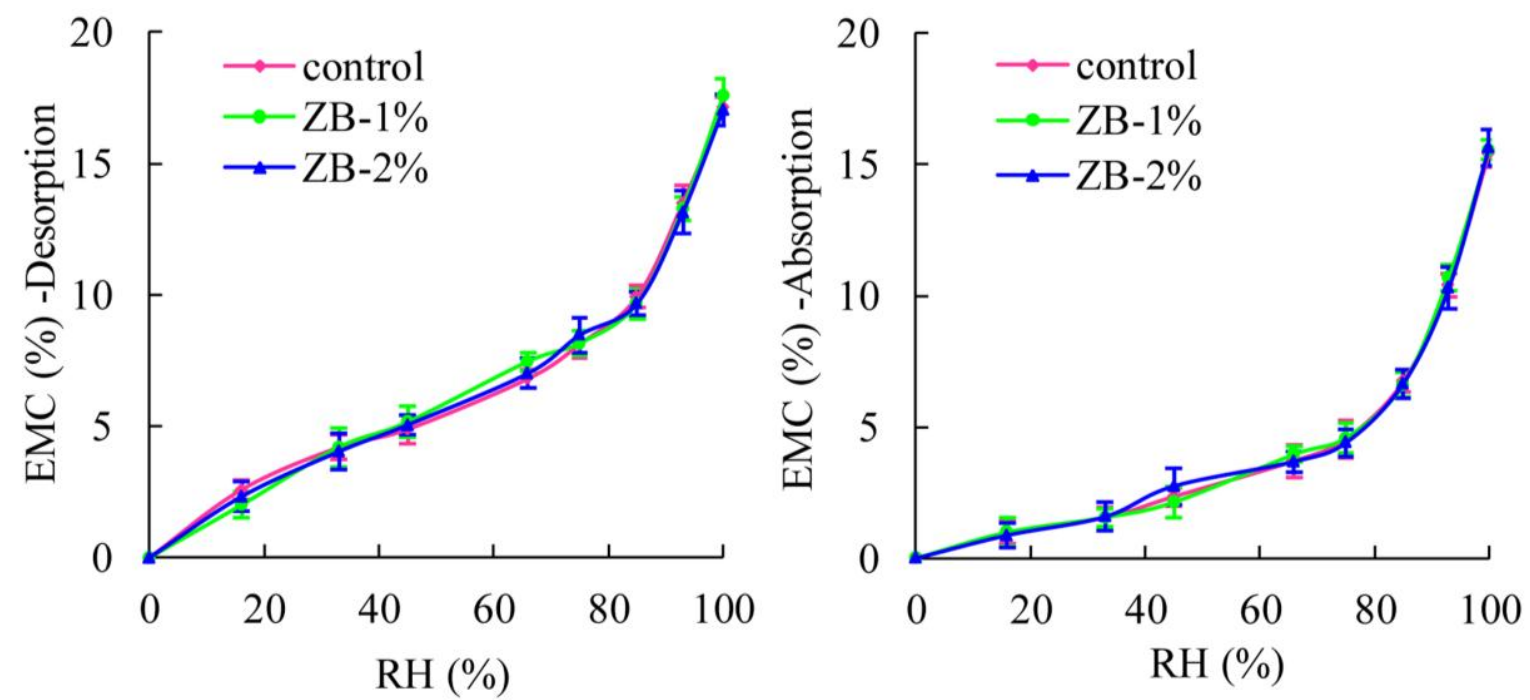

Figure 4. Effects of zinc borate (ZB) on EMC of WPCs.

\subsection{Nelson's Model Fit to Measured EMC}

Figure 5 shows typical graphs of the comparison between measured and predicted EMC data for WPCs (based on the data of WPC samples for type 1). Lines show sorption and desorption isotherm predicated by the model. The experimental EMC data were close to that of predicted by Nelson's model, presenting agreement with the model. Apparently, the absorption curve was lower than the desorption curve, indicating sorption hysteresis at a given $\mathrm{RH}$ level. 


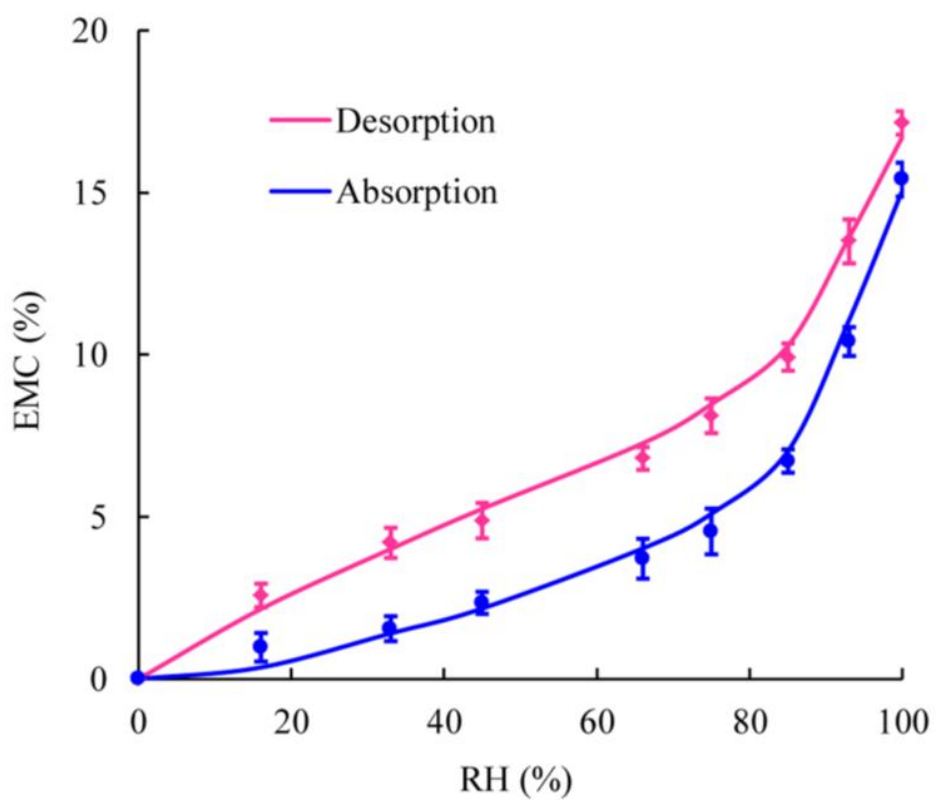

Figure 5. Comparison between calculated EMC by Nelson's model and measured EMC from experiments. Lines show values predicated by the model.

The regression analysis data on sorption isotherm for various materials is shown in Table 2. The values of parameters $A$ and $M v$ were different for various materials. These parameters can be used in Equation (3) to predict the EMC of different materials at a given RH level. The magnitude of $M v$ was higher in desorption than in absorption for all materials tested at a given RH. Among all these materials, WPCs showed the lowest magnitude of $M v$ both in absorption and desorption, averaging at 16.70 for absorption and 16.81 for desorption. Composite panels and solid wood had higher $M v$ values than WPCs. Figure 6 shows the comparison of sorption isotherm predicated by Nelson's model based on the parameters listed in Table 2 for different material types from desorption and adsorption. The sorption isotherm of WPCs is lower than that of the other three material types both for adsorption and desorption. It is demonstrated that WPCs is less accessible to water than solid wood and wood composite products under the same environment. This difference may be related to the characteristic of the materials. Compared to solid wood and wood composites, the wood components in WPCs are partial covered by the water-resistant plastic, which prevent the wood fibers from absorbing the water. In addition, WPCs contain only $55 \%$ of wood fiber by weight while the moisture content is calculated by the total weight of the WPCs, thus the EMC of WPCs are relatively smaller than solid wood and wood composites.

Table 2. Parameters of Nelson's sorption isotherm for different materials.

\begin{tabular}{|c|c|c|c|c|c|}
\hline \multirow{2}{*}{ Material } & \multicolumn{2}{|c|}{ Absorption } & \multicolumn{2}{|c|}{ Desorption } & \multirow{2}{*}{$\begin{array}{c}\text { Hysteresis ratio } \\
\text { (Ads./Des.) }\end{array}$} \\
\hline & $A(\mathrm{cal} / \mathrm{g})$ & $M_{v}(\%)$ & $A(\mathrm{cal} / \mathrm{g})$ & $M_{v}(\%)$ & \\
\hline WPC & 3.37 & 16.70 & 4.60 & 16.81 & 0.978 \\
\hline $\mathrm{MDF}^{\mathrm{a}}$ & 4.68 & 19.13 & 4.94 & 24.94 & 0.767 \\
\hline Aspen ${ }^{a}$ OSB ${ }^{a}$ & 4.49 & 22.94 & 4.89 & 28.28 & 0.8111 \\
\hline $\mathrm{SYP}^{\mathrm{a}}$ & 5.11 & 22.66 & 5.17 & 27.60 & 0.821 \\
\hline
\end{tabular}

${ }^{a}$ data are from $\mathrm{Wu}(1999)[19]$ at $25^{\circ} \mathrm{C}$. 

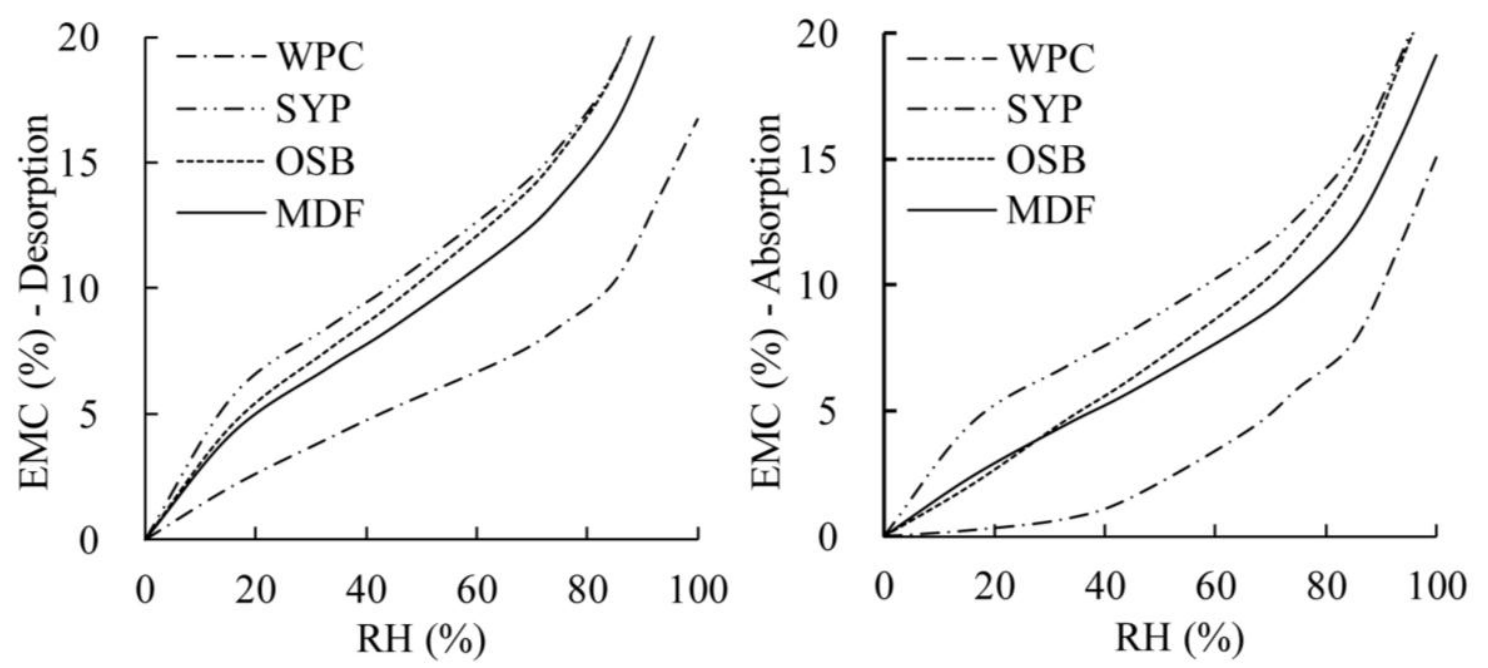

Figure 6. Comparison of sorption isotherm predicated by Nelson's model for different types of materials.

\section{Conclusions}

Within the scope of this study, the main conclusion is that WPCs demonstrate sorption and sorption hysteresis phenomena similar to wood and other wood-based composites. The other conclusions can also be drawn as follows:

- The additives such as ZB and UV stabilizers at the loading levels used have little effect on the EMC of WPCs under various RHs at $20^{\circ} \mathrm{C}$;

- The experimental data of EMC at various RHs fit to Nelson's sorption isotherm model well and the model can be used to predict EMCs of WPCs under different RH environmental conditions;

- The EMC of WPCs is significantly lower than solid wood and other wood-based composites due to less wood content and partially encapsulation of the wood fiber by plastic in WPC.

\section{Acknowledgments}

The authors gratefully acknowledge the financial support from the National Key Technology Research and Development Program of the Ministry of Science and Technology of China (Grant No. 2012BAD32B04) and from the National Natural Science Foundation of China (Grant No. 31170529).

\section{Author Contributions}

Feihong Liu conducted the experiments and data analysis, wrote the initial draft of the manuscript, and completed the revision of the manuscript. Guangping Han prepared the final manuscript. The study was overseen by Wanli Cheng and Guangping Han. Qinglin Wu conceived the project and prepared all the test samples. Qinglin $\mathrm{Wu}$ and Guangping Han reviewed and contributed a lot to the final revised manuscript. All authors read and approved the manuscript. 


\section{Conflicts of Interest}

The authors declare no conflict of interest.

\section{References}

1. Smith, P.M.; Wolcott, M.P. Opportunities for wood/natural fiber-plastic composites in residential and industrial applications. For. Prod. J. 2006, 56, 4-11.

2. Stark, N.M.; Matuana, L.M. Ultraviolet weathering of photostabilized wood-flour filled high-density polyethylene composites. J. Appl. Polym. Sci. 2003, 90, 2609-2617.

3. Schauwecker, C.; Morrell, J.J.; McDonald, A.G.; Fabiyi, J.S. Degradation of a wood plastic composite exposed under tropical conditions. For. Prod. J. 2006, 56, 123-129.

4. Fabiyi, J.S.; McDonald, A.G.; Wolcott, M.P.; Griffiths, P.R. Wood plastic composites weathering: Visual appearance and chemical changes. Polym. Degrad. Stab. 2008, 93, 1405-1414.

5. Stark, N.C. Photodegradation and Photostabilization of Weathered Wood Flour Filled Polyethylene Composites. Ph.D. Thesis, School of Forestry Resources and Environmental Science, Michigan Technological University, Houghton, MI, USA, 2003.

6. Stark, N.M. Considerations in the weathering of wood-plastic composites. In Proceedings of the 3rd Wood Fibre Polymer Composites International Symposium, Bordeaux, France, 26-27 March 2007.

7. Hon, D.N.S. Weathering and photochemistry of wood. In Wood and Cellulosic Chemistry; Hon, D.N.S., Shiraishi, N., Eds.; Marcel Dekker Inc.: New York, NY, USA, 2001.

8. Taib, R.M.; Ahmad Zauzi, N.S.; Mohd Ishak, Z.A.; Rozman, H.D. Effects of photo-stabilizers on the properties of recycled high-density polyethylene (HDPE)/wood flour (WF) composites exposed to natural weathering. Malays. Polym. J. 2010, 5, 193-203.

9. Wang, W.H.; Morrell, J.J. Water sorption characteristics of two wood-plastic composites. For. Prod. J. 2004, 54, 209-212.

10. Clemons, C.M.; Ibach, R.E. Effects of processing method and moisture history on laboratory fungal resistance of wood-HDPE composites. For. Prod. J. 2004, 54, 50-57.

11. Pendleton, D.E.; Hoffard, T.A. Durability of an extruded HDPE/wood composite. For. Prod. J. 2002, 52, 21-27.

12. Bastias, M.V.; Cloutier, A. Evaluation of wood sorption models for high temperatures. Maderas Cienc. Technol. 2005, 7, 145-158.

13. Chauhan, S.S.; Aggarwal, P. Effect of moisture sorption state on transverse dimensional changes in wood. Holz Roh Werkst. 2004, 62, 50-55.

14. Choong, E.T.; Achmadi, S.S. Effect of extractives on moisture sorption and shrinkage in tropical woods. Wood Fiber Sci. 1991, 23, 185-196.

15. Clemons, C.A.; Rowell, R.M. Moisture sorption properties of composites of boards from esterified aspen fiber. Wood Fiber Sci. 1992, 24, 353-363.

16. Simpson, W.T. Predicting equilibrium content of wood by mathematical models. Wood Fiber Sci. 1973, 5, 41-49.

17. Adebola, A.B.; Dawson-Andoh, B. Adsorption and desorption performance of two wood commercial wood plastic composites. For. Prod. Soc. 2008, 58, 32-36. 
18. Nelson, R.M. A model for sorption of water vapor by cellulosic materials. Wood Fiber Sci. 1983, $15,8-12$.

19. Wu, Q. Application of Nelson's Sorption isotherm to wood composites and overlays. Wood Fiber Sci. 1999, 31, 187-191.

20. Xu, X.W. The Thermal Property of Straw and Hygroscopic Property of Straw Particleboard. Ph.D. Thesis, Nanjing Forestry University, Nanjing, China, 2003.

21. Han, G.P.; Wu, Q.L. Comparative properties of sugarcane rind and wood strands for structural composite manufacturing. For. Prod. J. 2004, 54, 283-288.

(C) 2015 by the authors; licensee MDPI, Basel, Switzerland. This article is an open access article distributed under the terms and conditions of the Creative Commons Attribution license (http://creativecommons.org/licenses/by/4.0/). 